\title{
A TAle of Being Everything: Literary SubJect In Ruth OzeKI's $\boldsymbol{A}$ TALE FOR THE TIME BEING
}

\begin{abstract}
The article examines the structure of the literary subject in Ruth Ozeki's 2013 novel $A$ Tale for the Time Being from the perspective of the governing mechanisms of the postmodern epoch. I argue that the fluidity of the subject roles in the novel not only complies with Zen Buddhist principles Ozeki admittedly employed in their conception, but also reflects the structure of contemporary individuals within the postmodern social and economic realities. My analysis of the narrative agents relies primarily upon the theoretical framework charted by Jean Baudrillard, specifically his concepts of hyperreality and fractal subject. The adherence of the subjects in the novel to the principles of the postmodern paradigm allows us to consider A Tale for the Time Being as an example of a way in which the American mainstream has begun to accommodate (to) the social and historical circumstances of the new historical epoch.
\end{abstract}

Keywords

Fluidity; fractal subject; hyperreality; literary subject; narrative agents; postmodern fiction

\section{Introduction}

Primarily because of its placement within the American literary mainstream, ${ }^{1}$ A Tale for the Time Being, a 2013 novel by Canadian-American Ruth Ozeki, invites consideration in terms of how the governing principles of our postmodern epoch bear upon literature. The classification is just as much the result of the novel's marketing, the type of awards it won or was nominated for, and the critical 
and scholarly attention it has been receiving, as it is a matter of the novel's thematic and formal properties, which abide to no specific genre-determining conventions. Ozeki, a writer, film director, and Zen Buddhist priest, weaves myriad stands of reality into her text. The events, conveyed as they are in a veristic, factual manner, are located within familiar temporal and spatial locales, while the protagonists, along with their experiences and reasoning, strike us as convincing and credible.

At the same time, the polysemy of the novel's title turns out to be the defining feature of the novel's internal and external structures. This polysemy is paradigmatic of the story - in addition to the lack of an unequivocal denouement, the story's organisation impedes linear and causal summarizing, and there is no conclusive validation of the content in the sense of an unambiguous ending. Moreover, literary realities defy any definitive spatial or temporal placement as the narrative strands multiply forth in all directions, interconnect seemingly at random, and simultaneously open up new spaces for the narrated events and their realities. The categories of author, narrator, literary character and reader prove to be similarly indeterminate, since individual roles and corresponding identities constantly multiply and freely traverse from one to another.

The vantage point of this paper is precisely the seeming paradoxicality of the novel's distinct veristic rendering of contemporary experience, and the decidedly non-linear, dispersed, rhizomatous and fluid structure of the narrative realities, literary subjects, and formal organisation in general. The situation, however, is paradoxical only within the framework of Cartesian metaphysics and its intrinsic conceptualisations of reality and subject in terms of clearly defined binary oppositions. This is why Ozeki's third novel invites consideration from the perspective of a different historical framework.

The paper focuses on the status, the structure and the functioning of subject positions in the novel. This decision is primarily prompted by the fact that practically every piece of writing on the book - be it an interview with the author, a critical review, or a scholarly article - acknowledges the instability, multiplication, and interchangeability of the subject roles. These are generally discussed in terms of their compliance with the Buddhist principles, especially the notions of self and no-self which Ozeki admittedly employed in the structuring of her protagonists (cf. Hendry 2013; Pflug 2014; Ty 2013), or very generally attributed to recent trends in autobiographical fiction without considering the matter on a broader scale (cf. Davis 2015).

In an interview with Eleanor Ty (2013: 161), Ozeki explained that in this novel she was interested in conveying "the sense of the way the world is now". In line with her statement, I intend to examine whether the instability, interchangeability and fluidity of the subject roles, which Ozeki explains as a consequence of observing "basic Buddhist principles - of interdependence, impermanence, interconnectedness" (Ty 2013: 161) in the novel's structuring, also correspond to the characteristics of fiction determined by the principles governing the realities of postmodern societies and cultures. In order to do that, I analyse the characteristics 
of the narrative agents in Ozeki's novel in terms of the concepts that theoreticians of postmodernity, in their various treatments of the processes determining the social, economic, political and cultural spheres of the past seven decades, identify as paradigmatic for the functioning of contemporary realities and individuals within them. Establishing that the literary identities in the novel indeed comply with the structuring and the functioning of subjects within postmodern realities allows us to consider A Tale for the Time Being as a rare example of the way in which American mainstream fiction can thoroughly accommodate (to) the new social and historical circumstances. ${ }^{2}$ If such accommodation is the case, the properties intrinsic to the novel's internal and external structuring on the levels of content and form may provide insight into the modifications of the status, role and function of literature in the postmodern historical epoch.

\section{Ozeki, the novel, and their time}

A Tale for the Time Being is Ozeki's third novel. Like the first two, My Year of Meats (1998) and All Over Creation (2003), it seamlessly merges fiction with facts, features female Japanese-American protagonists, and thematises the various relations between Japanese and American traditions, examining the respective societies and cultures from multiple narrative perspectives. Ozeki started working on the novel in 2007 already. Her intention was "to write a story about the relationship between the writer and the reader" (Ty 2013: 164), and to convey "everything that has happened in the past decade, personally as well as globally, in the post-9/11 period and since the turn of the millennium" (Ty 2013: 161). After Ozeki had drafted the novel several times, the devastating tsunami that hit Japan in 2011 provided her with the idea of how to render the principles of the interdependence and interconnectedness of everything, which, in her view, were crucial to establishing the sense of contemporary existence (Ty 2013: 161).

The resulting narrative is a combination of two narrative voices: that of sixteen-year-old Nao, who, after spending most of her life in California, returns to Tokyo with her parents when her father loses his job as a programmer in the Silicon Valley, and Ruth, an elderly novelist who lives with her husband Oliver on an island in British Columbia. Walking on the beach one day, Ruth comes across a barnacle-encrusted plastic freezer bag containing a Hello Kitty lunchbox. In it, she finds Nao's diary in English, a bundle of old letters, a ragged notebook and an old wristwatch. The lunchbox seems to be part of the flotsam that washed up on western Canadian shores after the 2011 tsunami in Japan. Ruth immediately starts reading the diary, which is composed as a letter to the person that will read it. At the very beginning of the diary, Nao explains that this is the account of her last days on earth. However, before committing suicide due to accumulating problems at home and the brutal bullying she is subjected to at school, Nao wants to recount the life-story of her great-grandmother Jiko, a hundred-and-four-year-old Buddhist nun. She is not exactly successful at that as each attempt to document 
the life of her great-grandmother ultimately turns into an autobiographical description of her own life, in which Jiko plays an increasingly important role. Ruth becomes completely obsessed with finding out what happened to Nao, and the lives of the three women, along with their stories, become intricately intertwined.

The narrative is evidently located, at least for the most part, in contemporary social and cultural realities. The methodological framework I use in order to establish whether the contemporariness of the novel exceeds the mere temporal setting (in that it complies with the hitherto discernible properties of the current historical paradigm) primarily relies upon the concepts and terminology developed by Jean Baudrillard. For the purposes of my analysis, his notions of hyperreality and the fractal subject effectively capture the observations of other influential theoreticians of postmodernity; ${ }^{3}$ as well, both concepts fundamentally anticipate the role of media and information in postindustrial societies. ${ }^{4}$ This allows us for the purposes of greater clarity - to use both terms generically, i.e. in cases not specifically envisioned by Baudrillard but conceptually corresponding to the two notions. Additionally, since hyperreality and the fractal subject infer nonlinearity, fluidity, and networking, they also prove suitable tools for theoretical treatment of postmodern literary phenomena in terms of their correspondence to contemporary social, cultural and economic conditions.

Baudrillard notably defines hyperreality as a state in which simulation produces its own reality, and the models of reality precede reality itself. The real is

produced from miniaturized units, from matrices, memory banks and command models - and with these it can be reproduced an indefinite number of times. [...] It is no longer a question of imitation, nor of reduplication, nor even parody. It is rather a question of substituting signs of the real for the real itself. (Baudrillard 2004: 366)

In practical terms, the conditions for the described construction of reality are created through the spread and ubiquitous presence of electronic media in contemporary societies, and their subsequent digitalisation. Already in 1986, media theorist Friedrich Kittler envisioned the effects of the imminent equal coding of all media. He associated this coding with the end of the epoch of modernity, a period defined precisely by the historical emergence of different media (cf. Johnston 1998: 251):

The general digitalization of information and channels erases the difference between individual media. Sound and image, voice and text become mere effects on the surface, or, to put it better, the interface for the consumer. [...] In computers everything becomes number: imageless, soundless, and wordless quantity. And if the optical fiber network reduces all formerly separate data flows to standardized digital series of numbers, any medium can be translated into another. [...] [A] total connection of all media on a digital base erases the notion of the medium itself. (Kittler 1987: 102) 
Through the abolishing of the very concept of the medium, the reality of our sense perceptions and the resulting comprehension of the environment are fundamentally constructed by systems of digital computer codes. Under these conditions, the multitudes of information transmitted over a single, unified communication channel defy verification in the classical sense of their truthfulness as they refer to nothing substantial or real; they are simply an algorithm. According to Shannon's mathematical definition of information as a function of the probability of a message, the actual message is "one selected from a set of possible messages" (Shannon and Weaver 1949: 3), while the meaning is attributed to information by the processes that interpret it (Friedkin qtd. in Hayles 2014: 216). In practical terms, this means that each new piece of information - or information cluster - is verified from the perspective of its compatibility with the systems of information we have already received, verified and potentially assimilated into the hyperreality we perceive as the reality of our everyday existence.

The processes implicit in the transformation of the reality paradigm are connected to the modi operandi of postindustrial capitalism. After the Second World War, the rapid development of the advertising and media industries, coupled with information technologies, accelerated the capitalist modification of production relations. The act of buying is no longer related to the use or exchange value of the objects, but becomes consumption in the sense that these objects are appropriated as signs (cf. Baudrillard 1981: 66). Media-induced saturation with these signs facilitates the transformation of the Cartesian principle of subjectivity into what Baudrillard describes as "a fractal subject, both subdivisible to infinity and indivisible, closed on himself and doomed to endless identity" (2011: 64). As a decentred system of identical selves produced and producible from existing sign-objects, such a subject structurally corresponds to the structural logic of hyperreality since postmodern identity-creation also involves systematization of media-transferred information. Individuation, then, involves selection of sign-objects from a universally shared multiplicity of media products, and "is therefore not at all contradictory with mass status" (Baudrillard 2011: 64). The postmodern subject is a "subject without other" (Baudrillard 2011: 64), conceptually an infinite internal differentiation of the same subject (Strehovec 1994: 60). Baudrillard's notion of fractality thus implies both the self-same, metonymic structuring of the subject at every scale (we select our characteristics from the same fund of media products); moreover, his notion implies that the subject dimension exceeds the postmodern subject's topological dimension (the subjective dimension is the sum total of all the potential individual dimensions).

\section{Literary subjects and the postmodern paradigm}

In order to establish whether and how the subject positions in Ozeki's novel comply with the principles of the postmodern paradigm, I first consider the effects of applying the principles of subjectivity and identity creation within postmodern 
realities to the traditional categories of the participants in the story-telling act, i.e. the author, the narrator, the character and the reader. The findings serve as a methodological framework for the analysis of Ozeki's praxis, all the while keeping in mind that the novel is fundamentally a medium, that is, a generator of information; also, due to the implosion of media into a single communication channel, there is no ontological difference between the novel and any other medium. In the context of the postmodern paradigm, the representational potential of the novel therefore merges with the function of creating and conditioning hyperrealities. Henceforth, the pivotal assumption conditioning the Modern Age comprehension of literature - the dialectics of the real and the fictional - is effectively disqualified.

This examination of the postmodern status of the participants in the storytelling act in $A$ Tale for the Time Being rests on the premise that literary subjects can be considered postmodern if the strategies of their construction and the manner of their functioning correspond to the principles of subject creation and functioning intrinsic to the postmodern paradigm. From the perspective of Baudrillard's conceptualisation of the postmodern subject as fractal, postmodern literary subjectivities - like postmodern hyperrealities - are essentially networks of mediated data; they are systems of randomly appropriated but compatible signobjects that constitute the fractal subject's identity variants. Since the information for the identity construction is received via a single, unified communication channel of the digital medium, meaning that the materials for individuation are gathered from a common fund of identically coded characteristics, the categories of author, narrator, reader and literary character are rendered arbitrary, unstable and interchangeable because there are no fundamental differences between them. The digital medium thus effectively actualises poststructuralist understanding of textuality, as well as the concepts of author and reader. ${ }^{5}$

According to the rules of how the digital medium functions, the concepts of author and reader also coincide with the concept of literary character, as they are all fundamentally identity variants of one and the same subject, composed from qualitatively identical components in identical ways. In other words, the formation of a literary identity is synonymous and simultaneous with the composition of any given self as a hyperreal system that is constructed and constructible from media-generated information. That, in turn, eliminates the traditional differentiation between who is real, and who is fictive or (literary) fiction, and opens up the possibility of being simultaneously real and fictive, literary and non-literary.

Literary character - simultaneously a representation and a medium-generated sign-object - can thus be described as an identity variant of the author as incorporated within the identity variant of the reader in a way that can be considered autobiographical. However, such autobiographicality is not limited to the author alone but to all the involved participants, and it is not an account of an individual past but of all the possible realities of existence. Within the postmodern paradigm, the status of the participants in the literary act (i.e. those traditionally referred to as authors, narrators, characters, and readers) is thus that of fluid, intertwined and interchangeable decentred networks of mediated data. 


\section{Networks of Ozeki's time being(s)}

Considering Ozeki's praxis with regard to the presupposition that postmodern literary subjects are effectively networks of mediated information that are actualised as systems of randomly acquired but compatible media-transferred characteristics, we can observe that, in the broadest sense, all identities in the novel are mediated in various ways and to various degrees. Literary characters Nao, Jiko, Jiko's son Haruki I, Nao's father Haruki II, her mother and her classmates, are composed from information transferred to Ruth and the readers via Nao's diary, Haruki's letters and his secret notebook, Ruth's internet searches on them, and e-mailed correspondence between Ruth and the psychologist who supposedly treated Nao's father. On the fundamental level, Ruth's identity is likewise a system of personal features, the structure of which relies on mediated data, simply because she is a character in a novel. As such, she is established from information conveyed to us either by Ruth herself, or by other literary characters, especially her husband Oliver. However, the structuring of her identity as a multidimensional network significantly intensifies when the parallels between her and the novel's author are taken into account. They are both called Ruth and they are both writers, which prompts the reader to establish the connection immediately upon Ruth's introduction in the novel. ${ }^{6}$ That was, in fact, Ozeki's intention. In her characterisation of Ruth she anticipated that the "discerning reader would be able to find this out without any trouble [...] because there is a lot of biographical information about me in the world" (Ty 2013: 165).

Verification of information on Ruth from the novel with available information on Ozeki exhibits an extremely high degree of compatibility of both systems of identity. On the one hand, this degree of compatibility contributes to the stability of Ruth's identity; on the other, it corroborates interchangeability of the two identity variants. Assembled data confirm that Ruth in the novel lives a life that is very similar to that of Ozeki. They are both married to a landscape artist and ecological activist named Oliver; they both live in Whaletown on Cortes Island in British Columbia, where they moved to from New York. Their mothers, both Japanese, suffered and died of Alzheimer's disease, and they are both well acquainted with Japanese culture and literature. The similarities are sometimes incredibly detailed: at one point in the novel, Ruth, for example, mentions that she gave a plenary speech on the politics of food at a conference in 2001 - the very topic of the speech Ozeki gave at the conference of the REAP Society in Wisconsin the same year (cf. "Food for Thought Festival History"). The NeoEocene project Oliver is working on in collaboration with the Friends of the Pleistocene organisation in the novel, is one of the projects and a published essay by Ozeki's husband Oliver Kellhammer, who is also a member of Friends of the Pleistocene (cf. "Change Swarm" 2013). The implicit autobiographicality contributes to a greater stability of Ruth's identity, and ensures the fluidity, compatibility and interchangeability of the author, narrator and literary character as an infinite internal differentiation of the same - fractal - self. 
In accordance with such structuring, Ruth's system of identity not only merges with Ozeki's, but simultaneously also with Nao's and Jiko's. In the relationship between Ruth and Nao, it is impossible to establish which one is the mediator and which one is mediated, that is, who is the author and who the reader. Nao, by referring to her prospective reader as you, "calls Ruth into being" (Davis 2015: 93), giving the impression that Nao the author is conveying the story of Nao the character to Ruth the reader. But the roles are frequently reversed, or at least rendered indiscernible. In the "Epilogue", for example, Ruth's narration shifts from the third person to the first-person point of view that has so far been reserved for Nao's narrative. She asks the questions Nao asks at the beginning of her diary: "You wonder about me. I wonder about you. Who are you and what are you doing?" $(3,403)$ By exchanging the roles, the two become interchangeable. Similar blurring of roles is also observed in cases when Ruth starts to provide footnotes to her own sections of the text. This, according to Davis, "call[s] attention to Ruth's act of producing the text the reader holds, even as she is reading a received text" (2015: 94), all the while consolidating the interchangeability of Ruth and Ozeki. The disappearance of the text in Nao's diary, and subsequent mysterious re-filling of the blank pages, which ensures the continuation of Nao's story, can either be explained, as Oliver suggests, by means of quantum mechanics principles, or by acknowledging that Nao's story is, in fact, written by Ruth (or both). Such an assumption is corroborated through events such as this one: while reading Nao's diary, Ruth comes across the exact words Jiko uttered in the dream that Ruth had a week before.

Especially towards the end of the novel, Ruth's actions in dreams frequently interfere with the direction Nao's story is taking. For example, by informing Nao's father about his daughter's feelings and his grandmother's imminent death in one of her dreams, Ruth stops him from committing suicide and prompts him to help his daughter instead. A similar switching of roles takes place when, in a dream, Ruth places the secret diary, which Jiko's son was hiding under his shirt when he kamikazed his plane into the waves during WW2, into a box for Nao to find and put into the Hello Kitty lunchbox that Ruth discovers on the shore a few years later. From the secret diary, Nao learns the truth about his death - a truth that significantly alters her notions of bravery, real power, and ethical action in general.

The border between the two identities is additionally blurred in "Appendix A: Zen Moments", where the Zen concept of a moment as the basis for understanding the time being is explained. The segment opens with the first-person narrator's remark that she is conveying what the old Buddhist nun Jiko Yasutani explained to her in a dream. First-person narration, dreams about Jiko that Ruth frequently mentions, and familiarity with the teachings of Zen Buddhism in this segment prevent identification of the narrator of "Appendix A." What is more, the content additionally blurs the identities of the narrators in the main text. The narrator could be Ozeki, who in other appendices provides very factual explanations of key concepts addressed in the novel, which she further supports with a rather comprehensive list of relevant references. It could be Ruth, who, dreaming about 
Jiko, gets the idea of how to write the memoir she has been unsuccessfully trying to write for some time. It could also be Nao, who on the first page of the novel describes what Jiko explains to the narrator in the appendix, which brings forth the possibility that Nao is a younger version of Ruth, and her story is a fictionalized memoir of Ruth.

Consideration of the interference between Ruth's and Jiko's systems of identity opens up additional interpretational dimensions of this novel. In "Around the Gyre: Ruth Ozeki's A Tale for the Time Being", Ursula Pflug discusses the novel from the perspective of the Japanese prose genre shishōsetsu or I-novel. She argues that Ozeki's novel corresponds to the main tenets of such writing, which allows her to suggest that Jiko can be considered a facet of Ozeki, her alter ego: they both wrote an I-novel, they are both feminists, writers, activists, and Buddhist priests. Jiko's life can therefore be read as a variant of Ruth's life that Ozeki might live in a remote mountain temple. Such a reading corresponds to the principles of autobiographicality in I-novels, in which

the meaning derives from an extra-literary source, namely, the author's life. The Japanese as readers of shishōsetsu have tended to regard the author's life, and not the written work, as the definitive 'text' on which critical judgment ultimately rests and to see the work as meaningful only insofar as it illuminates the life. The Japanese reader constructs a 'sign' out of the signifying text and the signified extraliterary life, with no misgivings about this apparent blending of 'intrinsic' literary and 'extrinsic' biographical data. (Fowler 1988: xviii)

The value of the written is therefore just that of a reference to the lives of the authors, and language is merely a tool for the rendering of their experiences as thoroughly and from as many perspectives as possible. Since the author is established from the written, any literary identity in the novel can be considered authorial.

The last statement calls to mind the principles of creation of hyperreality and the fractal subject from media-transferred signs, effectively linking the concept of subjectivity in I-novels to the characteristics of postmodern literary subjectivities that have been inferred from the principles governing the postmodern paradigm. However, as striking as the similarities between the characteristics of literary subjects in I-novels and postmodern literary subjects may seem, it must be taken into account that I-novels function this way only within the specific context of Japanese tradition and culture (Fowler 1988: xviii). This consideration means that the similarities between them are correlative, and not causal. Nevertheless, both modes of identity creation facilitate the interference and merging of Ozeki's, Ruth's, Nao's and Jiko's identities in the same way as the identities of Haruki I and Haruki II merge through identical ethical principles, or those of Nao and Jiko's son through the brutal abuse they are subjected to. They function as identity variants of the same subjectivity in different spaces and times. 


\section{Time being everything}

Thus far, the analysis of Ozeki's praxis has shown that all the participants in Ozeki's story-telling act ultimately prove to be variations of the same subject, which ensures the autobiographical feel of the written. With that, Ozeki's praxis corresponds to the theoretical assumptions on the nature of postmodern literary subjects, as it implies the disappearance of the demarcation lines between the established concepts of author, narrator, reader and literary character. The novel's protagonists actually perform a number of functions simultaneously.

Ruth, due to her explicit connections with Ozeki, appears in the role of the author of the footnotes, and possibly of the novel. The latter is hinted at in the "Epilogue" and "Appendix A", and further corroborated by Ozeki's claim that this is a novel in which the character summons the author (Ty 2013: 162). Moreover, she performs the function of the third person narrator of Ruth's story, and conceivably also of Nao's story, a character in Ozeki's novel, and, when in her dreams she intervenes in Nao's reality, she becomes a character in Nao's story. She is also a reader of Nao's diary, of Haruki's letters and his notebook; she is their editor; and, by providing explanations for Japanese words and kanji in the footnotes, their translator and interpreter.

As a possible younger version of Ruth (and with that of Ozeki), Nao not only appears in the role of the author of the diary, but as the author of the novel as well. She is also the narrator of Nao's story, and - because of her interchangeability with Ruth - possibly of Ruth's story. Her authorial status is additionally corroborated by the fact that she effectively creates her readers - most obviously Ruth, but also Oliver, who also considers himself the recipient of the diary, and ultimately everyone reading the novel, as Nao's you can refer to the singular or the plural. Nao is also a character in Ozeki's novel and, if we consider the possibility that the missing pages of her diary are filled in by Ruth, a character in Ruth's story. She is furthermore the reader of her granduncle Haruki's letters and his secret diary, and, by being the you of Ruth's narrative in the "Epilogue", possibly the reader of Ruth's story.

Jiko, too, appears in various roles. First, she is an author of I-novels. An article on her writing, complete with footnotes and references to existing bibliographical resources, which Ruth finds in an online archive of scholarly journals, significantly reinforces the impression of her non-literary existence, even though the article is removed from the database a few days later. Also, if we consider the possibility that she is a facet of Ozeki and/or Ruth, she is perhaps the author of the (I-)novel in front of us. By giving her son's letters to Nao, and telling her about him, she is also the narrator of Haruki I's story, as well as a character in Ozeki's novel, Ruth's story and Nao's story. Lastly, she is a reader of Haruki's letters, which in turn establishes him as an author and the first-person narrator of his story.

Oliver also appears in various subject positions, albeit not as obviously as the female characters. His primary function seems to be that of a character in Ozeki's novel and in Ruth's story. However, the fact that he evidently feels just as much 
the addressee of Nao's you as Ruth does (344) in turn establishes him not only as a reader of Nao's story, but also as its author in the same manner as Ruth: he is the author summoned by the character, providing his version of the story and interfering with Ruth's. It is, after all, Oliver who suggests that the principles of quantum mechanics might explain the events in the story Ruth is possibly writing. To take matters further, it was Ozeki's husband Oliver Kellhammer who suggested the novel's title (Ty 2013: 169), and came up with the idea that she should "break the fictional container [...], step in and be in the book" (Doyle). With that, he, at least technically, takes on the role of the author of the novel.

Oliver from the novel and Oliver Kellhammer merge most obviously in footnote 160, in which the contributor of the footnote to Oliver's comment in the story states that "Oliver looked up the quote later and found it's from an article about quantum computing by Rivka Galchen, which appeared in the New Yorker, May 2, 2011" (395). In her interview with Anita Sethi, Ozeki explains that she decided to include the subject of quantum mechanics into the book when her husband sent her an article from the New Yorker. Needless to say, the article referred to in the novel actually exists (cf. Galchen), and that it was, in fact, the one that Kellhammer sent to Ozeki. ${ }^{7}$ Oliver thus also seamlessly incorporates himself into the network of the novel's literary identities, in which the subject roles and identity variants are fluid, intertwined, and interchangeable precisely because of the (fractal) logic of their creation.

The fluid, intertwined, and interchangeable nature of literary identities in the novel, forming an intricate, decentred network of subjectivity, becomes apparent when one considers the implications of Ozeki's remark that $A$ Tale for the Time Being is, partly, her memoir (Doyle). Ruth, too, is unsuccessfully struggling with a memoir, which may be the novel in front of us, ${ }^{8}$ while Nao's diary is in fact her memoir, which includes the memories of her great grandmother Jiko. Additionally, Haruki I is also writing a memoir, a double one at that. In the letters to his mother he describes his life in the military in the generic, formulaic way prescribed by the authorities and further depersonalized by the strict censors, while his secret diary contains emotional accounts of the torture and humiliation to which he and his comrades are subjected.

Within a single text, the readers therefore simultaneously read Ozeki's, Ruth's, Nao's, Jiko's and Haruki's memoirs. Their individual identities, together with the corresponding realities, thus merge within a single system of subjectivity, into which - by and through the act of reading - the identities of the novel's readers are incorporated as well. The readers, namely, verify the compatibility of the received information on the literary subjects against their own systems of identity, and interpret them accordingly. In other words, the systems of literary subjectivity interfere with the readers' systems of subjectivity and vice versa. It is, in fact, the readers who decide on the roles of the various systems of identity in the novel according to their own systems of identity. The roles of the author, narrator, literary character, and reader, as well as their construction and interconnectedness, are therefore assigned to the participants in the literary act by the 
reader of the novel. The reader's role merges with that of the author and of the narrator in the same way that Ruth in the book is established as the author and the narrator precisely because she is the reader. The described instances of interference and interchangeability of all, literary and non-literary, participants in the story-telling act correspond to my assumption that the construction of any literary identity is synonymous and simultaneous with the composition of any given self, constructed from media-generated information.

\section{Conclusion}

The vantage point of my investigation of the literary subject in Ruth Ozeki's A Tale for the Time Being was the seeming paradoxicality between the novel's apparent mainstream status, ensured by veristic depiction of contemporary reality and individuals within it, and the decidedly non-linear, rhizomatous quality of its internal and external structuring on the levels of both content and form, typically found in experimental and avant-garde fiction. The question I set out to answer was whether it is possible that the novel's mainstream status could, in fact, be the result of its non-linear, networked structuring. That would mean that $A$ Tale for the Time Being actualizes and reflects the ways in which we - inhabitants of contemporary postmodern social and historical spaces - perceive, experience, and comprehend ourselves and our realities, which was, admittedly, the author's intention.

I chose to establish the postmodern status of the novel by determining whether the instability, interchangeability and fluidity of its subject roles can be explained from the perspective of the impact the principles governing the realities of postmodern societies might have on literary fiction. The decision to focus on the literary subject - rather than on another aspect of the book - was made with an intention to offer an additional angle to the on-going theoretical and critical debates on A Tale for the Time Being, which predominantly consider the problematics of the subject roles in Ozeki's novel.

I examined the correspondence between literary identities in the novel and the governing principles of postmodernity in terms of their agreement with the features the majority of theoreticians observe as paradigmatic of contemporary social, historical and cultural circumstances that condition the structuring of reality and subjectivity, i.e. non-linearity, intertextuality, polyvalence, decentralisation, network and rhizomatous structuring, etc. For clarity's sake, I primarily relied on Baudrillard's categories of hyperreality and the fractal subject, as they anticipate all the stated qualities, and conceptually correspond to the dominant postmodern medium.

From the perspective of Baudrillard's principles of subjectivity and identity creation within postmodern realities, postmodern literary subjects are structured as networks of mediated data, that is, as systems of randomly appropriated, media-generated characteristics. Essentially clusters of data, these characteristics are 
received through a single communication channel of the digital medium, and therefore gathered from a common fund of identically coded features. As a consequence, the logic of literary character creation corresponds to the building of any given identity, which effectively disqualifies the difference between real and fictional identities, while also contributing to the (auto)biographical feel of the written. Additionally, the principle of fractality renders the categories of author, narrator, reader and literary character arbitrary, unstable and interchangeable.

In her attempt to present the world as it is now, observing the Buddhist principles of "interdependence, impermanence, interconnectedness" (Ty 2013: 161), Ozeki bestows the qualities of fluidity, interference, interconnectivity, and interchangeability, which are also typical of postmodern reality and identity construction, upon (her) literary identities and their corresponding realities. The analysis of the subject-roles in A Tale for the Time Being from the perspective of their adherence to the current social, economic and historical conditions has further confirmed that the identities the novel establishes correspond to the fractal nature of our postmodern selves. The novel's author, the characters, narrators, as indeed the readers, constitute identity variants of a single subject, and are established as systems of randomly appropriated, compatible media-transferred characteristics. As such, the participants in Ozeki's story-telling act eradicate the boundaries between the real and the fictional, and ensure the (auto)biographical impression of the text.

It seems that the answer to the question that triggered this discussion - namely whether the novel's verism and contemporaneity are, actually, conditioned by its non-linear, networked structuring - is a conclusive yes. A Tale for the Time Being convincingly exhibits characteristics increasingly revealed as a paradigm for the functioning of postmodern societies, cultures, and science. The novel's placement within American mainstream fiction signals that the concepts hitherto largely confined to postmodern critical theory, genre, and experimental fiction, now fully determine the actual experience of being in our time.

\section{Notes}

1 The differentiation between genre and mainstream literature in this article is based on Brian McHale's adaptation of Evan-Zohar's distinctions within the literary system, which McHale applies to contemporary American prose (cf. McHale 1992: 227).

2 In the context of American genre fiction, such adaptation of the thematised realities and subjects to the new social and historical conditions was performed by cyberpunk fiction in the early 1980s (cf. Hayles 1994; Johnston 1998; Tabbi 1995). American experimental and avant-garde prose most notably reacted to the new circumstances at the end of the 1980s and the beginning of the 1990s with the production of the Avant-Pop movement (cf. Krevel 2010; McCaffery 1995; Landon 1995). The response of mainstream fiction to the reality of the media-governed society and consumerist culture has been, conversely, generally that of a detached observer, thematising and criticising the new circumstances from a perspective still fundamentally pertaining to the Cartesian tradition.

I am referring to theoreticians who in their treatments of the phenomena, related to the modi operandi of postindustrial societies, emphasise the principles of non-linearity, rhizomatous 
structuring, intertextuality, multivocality, decentring and networking (cf. Debord, Deleuze and Guattari, Derrida, Lyotard). The decision to rely upon their insights was prompted by the fact that these categories correspond to the structuring and functioning of the dominant digital medium (cf. Landow 1997: 33-48), which on the one hand reflects current social and cultural circumstances, and on the other hand conditions them according to its properties (Bolter 2001: 13, 17-21).

4 Baudrillard develops the concept of hyperreality in connection to the role of media in the creation of the Watergate scandal (2004: 370-371), and describes the production of hyperreality as algorithmic, in the sense of the virtual reality of the computer code (2004: 366).

5 This is in line with Landow's observation that Barthes, Derrida, Foucault and others treat "the self of author and reader not simply as (print) text but as hypertext. For all these authors, the self takes the form of a decentered (or centerless) network of codes that, on another level, also serves as a node within another centreless network" (Landow 1997: 91).

6 The need for further verification of the parallels between the two is triggered not only by their having the same name and the same occupation. As Davis observes, "[i]dentifying with Ruth as reader, the book's readers also scour the Internet for information on Ozeki, probably delighting in finding proof of her 'real' existence" (2015: 95). In addition, the novel's footnotes and appendices, which are extremely factual and refer to stable and verifiable segments of our everyday reality, are composed in a way that renders it impossible to establish whether their author is Ruth or Ozeki, prompting the readers to verify their statuses through further research.

7 Ozeki confirmed that during a Skype interview I co-conducted as part of a panel dedicated to her writing on 23 April 2016 at the EAAS conference in Constanta, Romania (April 22-25). In her interview with Jessica Doyle, Ozeki mentions that $A$ Tale for the Time Being is Ruth's failed memoir: failed because the only way a memoir can fail is that it turns into fiction (Doyle), which is what Ozeki hints happened to A Tale for the Time Being.

\section{Acknowledgements}

The author acknowledges the financial support from the Slovenian Research Agency (research core funding No. P6-0265).

\section{References}

Baudrillard, Jean (1981) For a Critique of the Political Economy of the Sign. US: Telos.

Baudrillard, Jean (2004) 'Simulacra and Simulations'. In: Rivkin, Julie and Michael Ryan (eds.) Literary Theory: An Anthology. Maiden: Blackwell Publishing, 365-377.

Baudrillard, Jean (2011) Impossible Exchange. London: Verso.

Bolter, Jay D. (2001) Writing Space: Computers, Hypertext, and the Remediation of Print. Mahwah: Lawrence Erlbaum Associates.

'Change Swarm' (2013) Friends of the Pleistocene, 5 Apr. Available online at: https://fopnews. wordpress.com/2013/04/. Accessed on 23 December 2016.

Davis, Rocio G. (2015) 'Fictional Transits in Ruth Ozeki's A Tale for the Time Being'. Biography 38 (1), 87-104.

Doyle, Jessica (n.d) 'An Interview with Ruth Ozeki'. Abebooks.com. Available online at: http:// www.abebooks.com/books/authors/ruth-ozeki-interview.shtml. Accessed on 14 February 2017.

'Food for Thought Festival History' (n.d.) REAP Food Group. Available online at: http://www. reapfoodgroup.org/events/food-for-thought/festival-history. Accessed on January 2017.

Fowler, Edward (1988) The Rhetoric of Confession. Shishōsetsu in Early Twentieth-Century Japanese Fiction. Berkeley: University of California Press. 
Galchen, Rivka (2011) 'Dream Machine'. The New Yorker, 2 May 2011. Available online at: http:// www.uvm.edu/ pdodds/files/papers/others/2011/galchen2011a.pdf. Accessed on 15 January 2017.

Hayles, N. Katherine (1994) Chaos Bound. Orderly Disorder in Contemporary Literature and Science. Ithaca: Cornell University Press.

Hayles, N. Katherine (2014) 'Cognition Everywhere: The Rise of the Cognitive Unconscious and the Costs of Consciousness'. New Literary History 45 (2), 199-220.

Hendry, Diana (2013) 'A Tale for the Time Being, by Ruth Ozeki - Review'. The Spectator, 30 March 2013. Available online at: http://www.spectator.co.uk/2013/03/on-the-beach-5/ Accessed on 15 March 2016.

Johnston, John (1998) Information Multiplicity: American Fiction in the Age of Media Saturation. Baltimore: The Johns Hopkins University Press.

Kittler, Friedrich (1987) 'Grammophone, Film, Typewriter'. October 41: 101-118.

Krevel, Mojca (2010) Izvidniki v puščavi resničnosti. Ljubljana: Sophia.

Landon, Brooks (1995) 'The Literature of Information'. In: Amerika, Mark and Lance Olsen (eds.) In Memoriam to Postmodernism. Essays on the Avant-Pop. San Diego: San Diego State University Press, 81-85.

Landow, George P. (1997) Hypertext 2.0. The Convergence of Contemporary Critical Theory and Technology. Baltimore: The Johns Hopkins UP.

McCaffery, Larry (1995) ‘Avant-Pop: Still Life After Yesterday’s Crash’. In: McCaffery, Larry (ed.) After Yesterday's Crash. The Avant-Pop Anthology. Middleborough: Penguin, xi-xxxi.

McHale, Brian (1992) Constructing Postmodernism. New York: Routledge.

Ozeki, Ruth (2013) A Tale for the Time Being. New York: Penguin Books.

Pflug, Ursula (2014) 'Around the Gyre: Ruth Ozeki's A Tale for the Time Being'. The New York Review of Science Fiction, 12 October 2014. Available online at: http://www.nyrsf.com/2014/10/ ursula-pflug-around-the-gyre-ruth-ozekis-a-tale-for-the-time-being.html. Accessed on 14 December 2016.

Sethi, Anita (2013) 'Ruth Ozeki: "This book is about the character creating a novelist"'. The Guardian, 7 March 2013. Available online at: http://www.theguardian.com/books/2013/mar/07/ruthozeki-interview-time-being. Accessed on 15 December 2016.

Shannon, Claude E. and Warren Weaver (1949) The Mathematical Theory of Communication. Urbana: University of Illinois Press.

Strehovec, Janez (1994) Virtualni svetovi. K estetiki kibernetične umetnosti. Ljubljana: Znanstveno in publicistično središče.

Tabbi, Joseph (1995) Postmodern Sublime: Technology and American Writing from Mailer to Cyberpunk. London: Cornell University Press.

Ty, Eleanor (2013) ““A Universe of Many Worlds”: An Interview with Ruth Ozeki'. Melus 38 (3): $160-171$.

Mojca Krevel, Ph.D., is associate professor of literatures in English at the English Department of University of Ljubljana. Her research focuses on those phenomena in contemporary American prose, which correspond to the metaphysical framework of postmodernity. Her areas of interest include contemporary prose, critical theory, new media, posthumanism and cybercultures. She is the author of monographs on cyberpunk (Kiberpank v literaturi, 2001) and the Avant-Pop movement (Izvidniki v puščavi resničnosti, 2010), co-author of Miracles of Rare Device: English Verse from the Elizabethans to the Moderns (2009) and the editor of Becoming World: Probing Hybridity in Postmodern American Fiction (2017).

Address: Dr. Mojca Krevel, English Department, Faculty of Arts, Aškerčeva 2, 1000 Ljubljana, Slovenia. [e-mail: mojca.krevel@ff.uni-lj.si] 
